\title{
Improvement of Reservoir Rule Curves using Grey Wolf Optimizer
}

\author{
Natpitak Sinthuchai and Anongrit Kangrang \\ Faculty of Engineering, Mahasarakham University, Kantharawichai District, \\ 44150 Maha Sarakham, Thailand \\ anongrit.k@msu.ac.th
}

\begin{abstract}
The purpose of this research was to apply the optimization method by the specific technique of Grey Wolf Optimizer (GWO) cooperating with the reservoir simulation model in order to improve the rule curves of reservoirs. The minimal average water shortage, the minimal average excess water, the minimal frequency of water shortages, the minimal frequency of excess water were used as the objective functions for searching procedure. This study considered the monthly data of reservoir rule curves from the Ubolratana reservoir, Khon Kaen Province, the Lampao reservoir, Kalasin Province and the Nam Oon reservoir, Sakon Nakhon Province as the case studies. Moreover, this study synthesized 1,000 samples of inflow data in order to evaluate the efficiency of new rule curves from the proposed model. The results were displayed the situations of water shortage and excess water in term of frequency, duration time, average water quantity and the highest water quantity. The results shown that four objective functions above can produce new rule curves which their physicals were similar to the current ones for all reservoirs due to the influences of seasonal inflow and the same operation conditions. The results after testing the new rule curves compared with the current ones show that the new rule curves improved by the objective function of minimal average water shortage can mitigate excess water and water shortage situations better than other rule curves produced by other objective functions and also better than current rule curves for all reservoirs. The results can conclude that GWO with the objective function of minimal average water shortage connecting with reservoir simulation model has more efficiency to search optimal rule curves.
\end{abstract}

Key words: Reservoir rule curves, optimization techniques, grey wolf optimizer, reservoir operation, frequency, objective functions

\section{INTRODUCTION}

Water is an important natural resource for living of plants and animals including our human life. There are many various fields of water demand such as consumption, agriculture, industry, irrigation, power generation, fisheries, transportation, tourism and ecological treatment. Because water is a limited resource whereas increase in population and social economic growth, so, the water demand is increased. These conditions are making the trend of future water crisis (Jain et al., 1998; Afshar, 2013; Hormwichian et al., 2018).

Reservoir is directly related to water resources management. Reservoir rule curves are used as the guideline in reservoir operation which refers to the storage of water in reservoirs and the delivery of water from reservoirs for various purposes (Akinro et al., 2007). Water resources management together with other resources as well as stakeholder participation is performed for allocating among of water for each water demand sector both current and future situations (Sivanpheng and Kangrang, 2015). An improvement of reservoir operation is one method of managing water in reservoirs that is not wasteful, budgetary and efficient. Therefore, it is necessary to have the reservoir rule curves in which to use as the appropriate control curve (M-Dawam and Ku-Mahamud, 2016; Hematpour et al., 2017). To find optimal rule curves, optimization techniques are applied in many cases. Firstly, reservoir simulation model with trial and error is used to find the appropriate rule curves (Zhou and Gou, 2013). Then dynamic programming is applied to connect with reservoir simulation for searching optimal rule curves (Chaleeraktrakoon and Kangrang, 2007; Kumar et al., 2010; Ji et al., 2014). Later many search optimal techniques are applied to connect with the reservoir simulation model for searching optimal rule curves, for example, Genetic algorithm, simulated annealing algorithm, differential evolution algorithm, cuckoo search algorithm and ant colony optimization technique etc. (Chang et al., 2005; Hormwichian et al., 2009;

Corresponding Author: Anongrit Kangrang, Faculty of Engineering, Mahasarakham University, Kantharawichai District, 44150 Maha Sarakham, Thailand, anongrit.k@msu.ac.th 
Prasanchum and Kangrang, 2018; Afshar et al., 2015; Ming et al., 2015; Kangrang et al., 2016, 2018, 2019).

Now a days, another method of finding suitable interest values is the new meta-heuristic method that used to determine appropriate water allocation criteria namely called the Gray Wolf Optimizer (GWO) (El-Fergany and Hasanien, 2015; Sulaiman et al., 2015; Jebaraj and Keshavan, 2017). In this way, inspiration comes from the gray wolf and search methods improving the surrounding position and hunting for natural forms of gray wolves. Based on the hunting behavior of gray wolves, it requires skill and ability to search for prey and surround them (Mirjalili et al., 2014; Saremi et al., 2015).

Therefore, the application of GWO with reservoir simulation model for searching optimal rule curves was performed in this study. The Ubolratana reservoir, Khon Kaen Province, the Lampao reservoir, Kalasin Province and the Nam Oon reservoir, Sakon Nakhon Province were considered as the case studies.

\section{MATERIALS AND METHODS}

Reservoir operation model: This study created the reservoir simulation model that using the water balance concept of the HEC-3 Model (US Army Corps of Engineers, 1974; Janoski et al., 2006; Hossain, 2016). Using the same principles as the above model to make it easier to connect with the techniques of gray wolf techniques and future development. This model can be used to evaluate for both water shortage situation and the excess water situations (in term of frequency, magnitude and duration).

In the beginning of the calculation, the amount of water storage in the reservoir was fixed at the full level or the full capacity. Then available water of 1 st month (January) was calculated using the water balance concept. Next, the monthly release was considered using the relationship between available water and water demand as shown in standard operating rule in Fig. 1 and Eq. 1. The lower rule curve and upper rule curve of each month were displayed in the standard operating rule too.

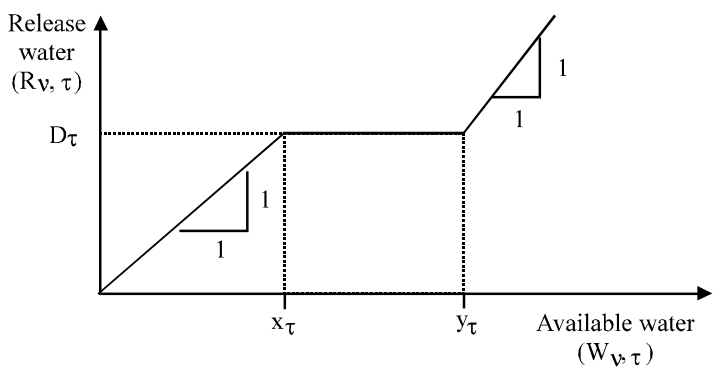

Fig. 1: Standard operating rule

$$
R_{v, \tau}=\left\{\begin{array}{l}
D_{\tau}+W_{v, \tau}-y_{\tau}, \text { for } W_{v, \tau} \geq y_{\tau}+D_{\tau} \\
D_{\tau}, \text { for } x_{\tau} \leq W_{v, \tau}<y_{\tau}+D_{\tau} \\
D_{\tau}+W_{v, \tau}-X_{\tau}, \text { for } x_{\tau}-D_{\tau} \leq W_{v, \tau}<x_{\tau} \\
0, \text { otherwise }
\end{array}\right.
$$

Where:

$\mathrm{R}_{\mathrm{v}, \tau}=$ The Release of water during year $\mathrm{v}$ and month $\tau$

$\tau=1-12$ representing January to December

$\mathrm{D}_{\tau}=$ The net water Demand during month $\tau$

$\mathrm{x}_{\tau}=$ The lower rule curve of month $\tau$

$\mathrm{y}_{\tau}=$ The upper rule curve of month $\tau$

$\mathrm{W}_{\mathrm{v}, \tau}=$ The available Water by calculating the water balance concept during year $v$ and month $\tau$ as described in Eq. 2:

$$
\mathrm{W}_{v, \tau+1}=\mathrm{S}_{v, \tau}+\mathrm{Q}_{v, \tau}-\mathrm{R}_{v, \tau}-\mathrm{E}_{\tau}
$$

Where:

$\mathrm{S}_{\mathrm{v}, \tau}=$ The stored water at the end of month $\tau$

$Q_{v, \tau}=$ The monthly inflow to the reservoir

$\mathrm{E}_{\tau}=$ The average value of the evaporation loss

The operating policy usually reserves the available Water $\left(W_{v, \tau}\right)$ for mitigating the risk of water shortage in the future when $0 \leq W_{v, \tau},<x_{\tau}-D_{\tau}$ under long term operation.

Application of grey wolf optimizer connecting with reservoir simulation: The calculation of optimal rule curves by using GWO connecting with reservoir simulation model started from collecting all input data and defining the purpose of the work number of work cycles, the number of times to improve the position of the hunting of the gray wolf. Next, tracking the chase and approaching the surrounding victims and attacking the victim until it stops moving were set (Fig. 2). These were the selection of the rule curves for each month from January to December. The amounts of 24 values were created as initial upper and lower rule curves. After that bring the created rule curves to use in reservoir simulation model. Then the reservoir operation was performed along the historic inflow data. The monthly water releases for all considered inflow years were obtained. These monthly water releases were used to calculate the objective functions. There were 4 objective functions; the minimal frequency of water shortage, the minimal frequency of excess release water, the minimal average water shortage and the minimal average excess release water that used to search optimal rule curves for all reservoirs. Each objective function was used to search until got the optimal rule curves. Then the value of objective function was evaluated for checking the stop criteria. If didn't meet the criteria, the process will go to the selection rule curves 


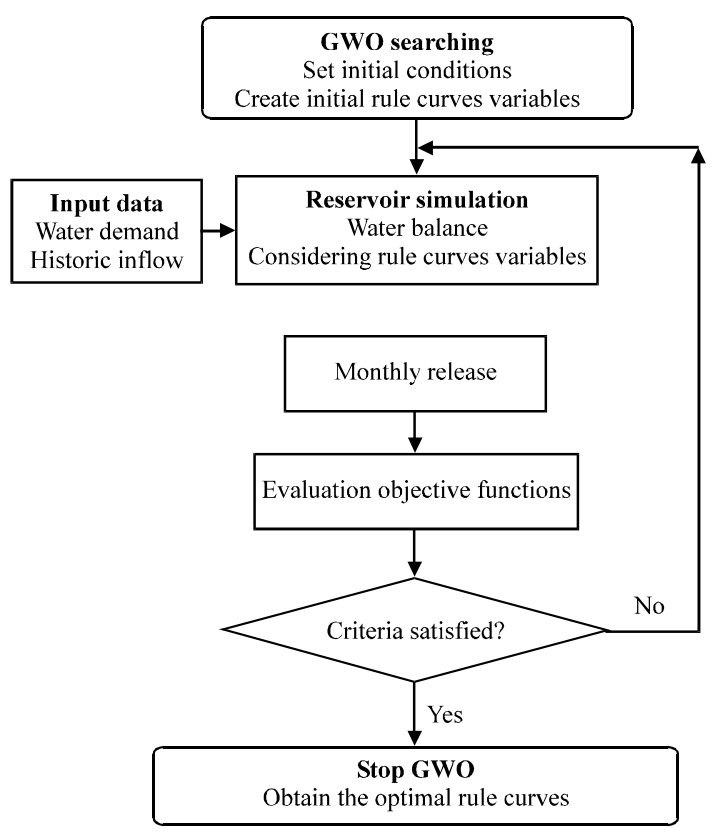

Fig. 2: Applying GWO for searching optimal rule curves

process again. The process will do until get the appropriate rule curves and stop. All objective functions were shown in Eq. 3-6 as the following.

$$
\operatorname{Min}(\text { Aver_Sh })=\left(\frac{1}{n} \sum_{v=1}^{n} \operatorname{Sh}_{v}\right)
$$

Where:

$\mathrm{n}=$ The length of the data set, the amount of water storage

$\mathrm{Sh}_{\mathrm{v}}=$ Water Shortage

$\mathrm{v}=$ The amount of water that is released is less than the target for water use)

In the case of searching for the answer, the upper control curve for the year of the water will change the function. This study uses the lowest average water shortage. The answer is the lowest average water volume as Eq. 4:

$$
\operatorname{Min}(\text { Aver_Ex })=\left(\frac{1}{n} \sum_{\mathrm{u}=1}^{\mathrm{n}} \mathrm{Ex}_{\mathrm{u}}\right)
$$

where, $\mathrm{Ex}_{\mathrm{u}}$ Excess water volume in the year (the amount of water released over the target of water demand).

\section{Illustrative application for searching optimal rule curves:}

In this study, the proposed GWO connecting reservoir simulation model was used to search the optimal rule curves of 3 reservoirs where located in the Northeast Region of Thailand (Fig. 3-5). The historic inflow data of

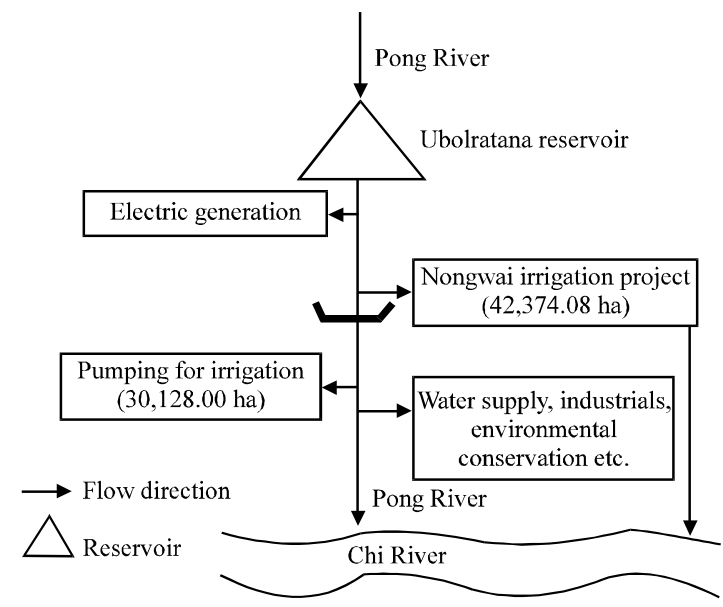

Fig. 3: Schematic diagram of the Ubolratana reservoir

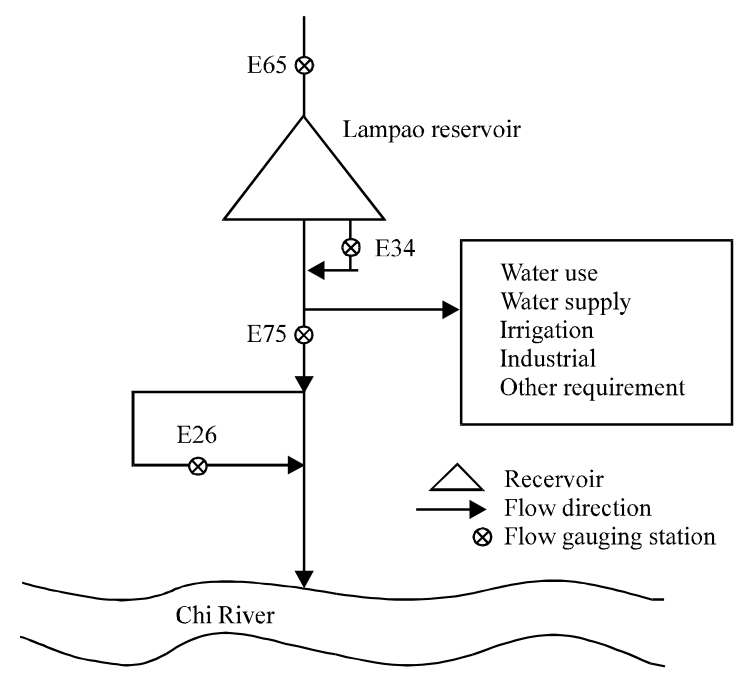

Fig. 4: Schematic diagram of the Lampao reservoir

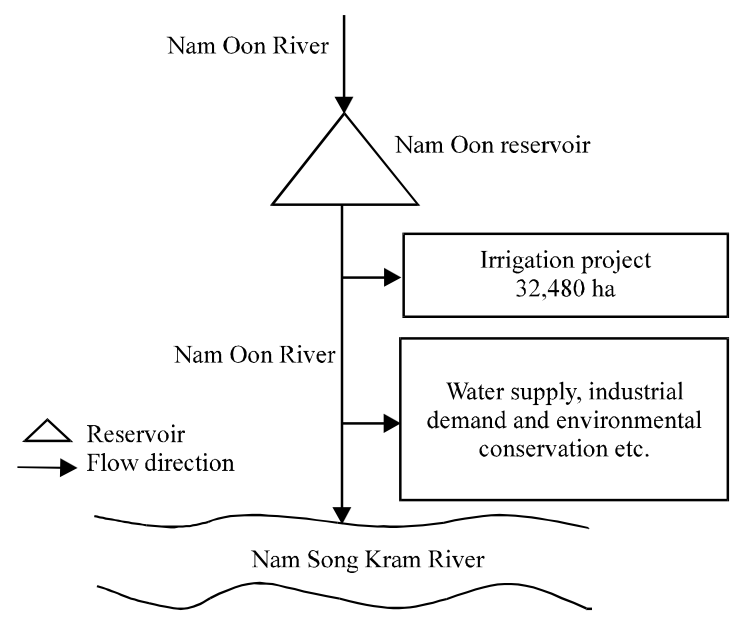

Fig. 5: Schematic diagram of the Nam Oon reservoir 
each reservoir were used in searching process. After got the obtained rule curves of each reservoir, these new obtained rule curves were used to evaluate the efficiency by considering the synthetic inflow data for 1,000 samples of each reservoir. First reservoir was the Ubolratana reservoir located in Khon Kaen Province. The historic inflow record from 1970-2017, monthly water demand, hydrologic data and physical characteristic of the reservoir were collected for searching and evaluating processes. The second reservoir was Lampao reservoir where located in Kalasin Province. Historic in flow data were collected from 1971-2017. Monthly water demand, hydrologic data and physical characteristic of the reservoir were collected for searching and evaluating processes. The third reservoir was Nam Oon reservoir where located in Sakon Nakorn Province. Historic in flow data were collected from 1993-2017. Monthly water demand, hydrologic data and physical characteristic of the reservoir were collected for searching and evaluating processes. The results of evaluation obtained rule curves were shown in term of situations of water shortage and excess water (frequency, magnitude and duration time).

\section{RESULTS AND DISCUSSION}

Optimal rule curves: Figure 6 shows the optimal rule curves of the Ubolratana reservoir for all objective functions as well as the existing rule curves. It indicates that GWO1-fre-short stand for the obtained rule curves from the proposed model considering the minimal frequency of water shortage as the objective function in searching procedure. GWO2-fre-spill stand for the obtained rule curves from the proposed model considering the minimal frequency of excess water as the objective function in searching procedure. GWO3-avr-short stand for the obtained rule curves from the proposed model considering the minimal average water shortage as the objective function in searching procedure. GWO4-avr-spill stand for the obtained rule curves from the proposed model considering the minimal average excess water as the objective function in searching procedure. They present that the new upper rule curves during May to September are higher than the upper existing rule curves. Whereas the new lower rule curves during March to June are lower than the lower existing rule curves. This makes it possible to store water to meet the water demand for irrigated areas during the dry season and reduce water shortage. However, the pattern of new obtained rule curves and the pattern of existing are similar according to the other studies (Hormwichian et al., 2009; Kangrang et al., 2016, 2018) whereas each study used differently optimization techniques.

Figure 7 shows the optimal rule curves of Lampao reservoir for all objective functions as well as the existing rule curves. It indicates that GWO1-fre-short, GWO2-fre-spill, GWO3-avr-short and GWO4-avr-spill represent the obtained rule curves from the proposed model considering the minimal frequency of water shortage, the minimal frequency of excess water, the minimal average water shortage and the minimal average excess water as the objective function in searching procedure, respectively. They present that the new obtained rule curves of Lampao reservoir are closed to the existing rule curves for all objective function. Furthermore, their patterns are similar like the previous studies (Hormwichian et al., 2009; Kangrang et al., 2016) whereas each study used differently optimization techniques connecting with reservoir simulation model.

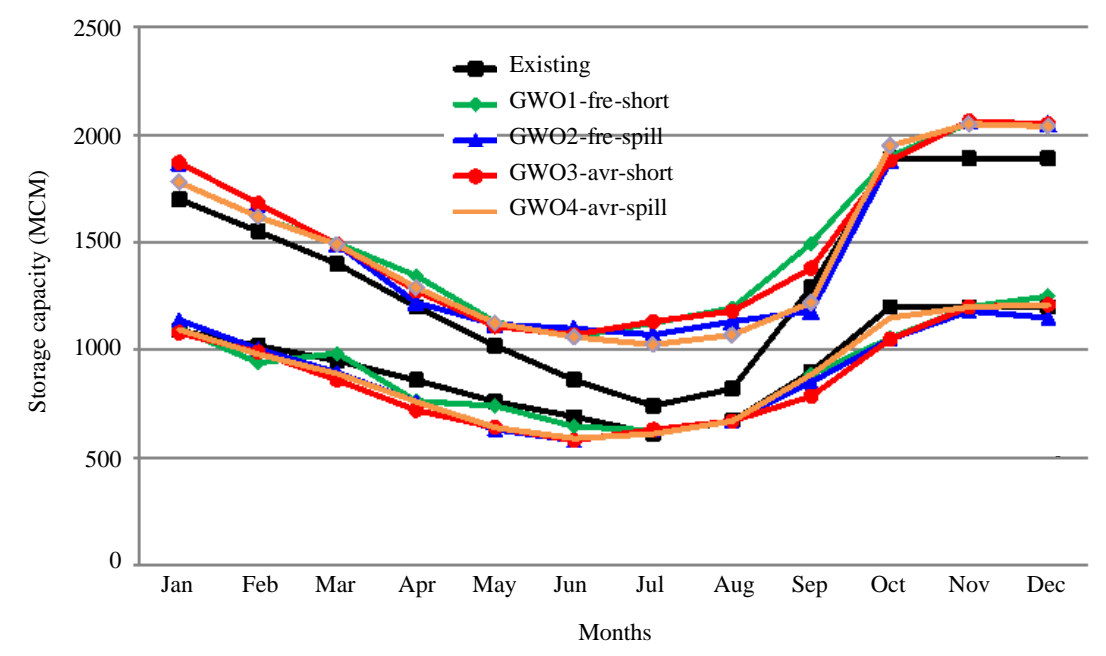

Fig. 6: Optimal rule curves of Ubolratana reservoir 


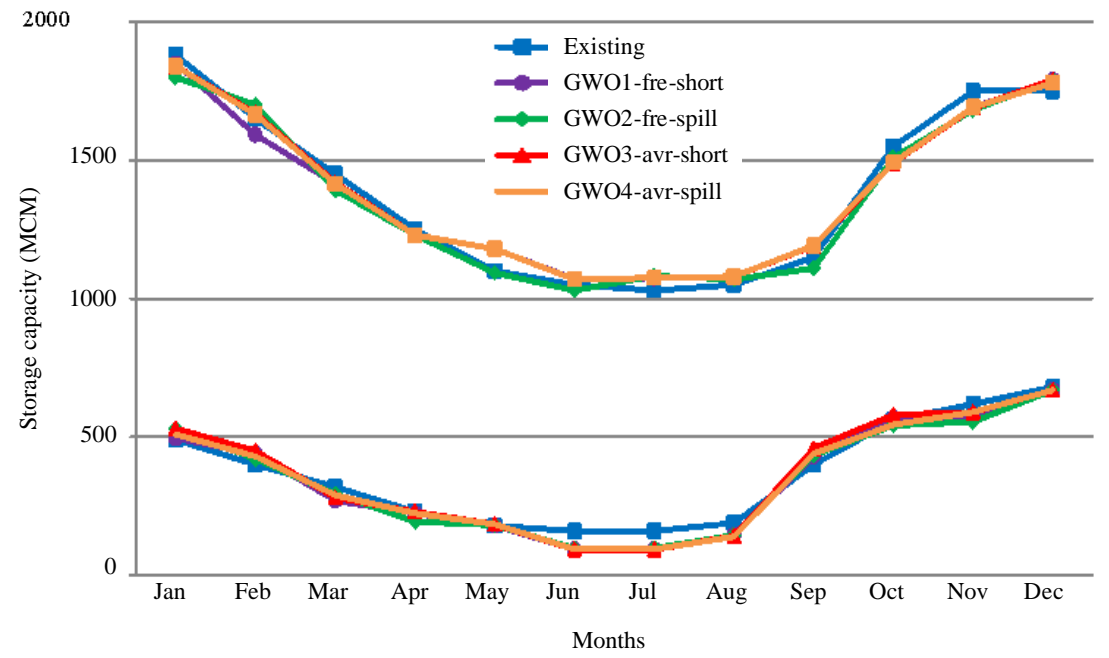

Fig. 7: Optimal rule curves of Lampao reservoir

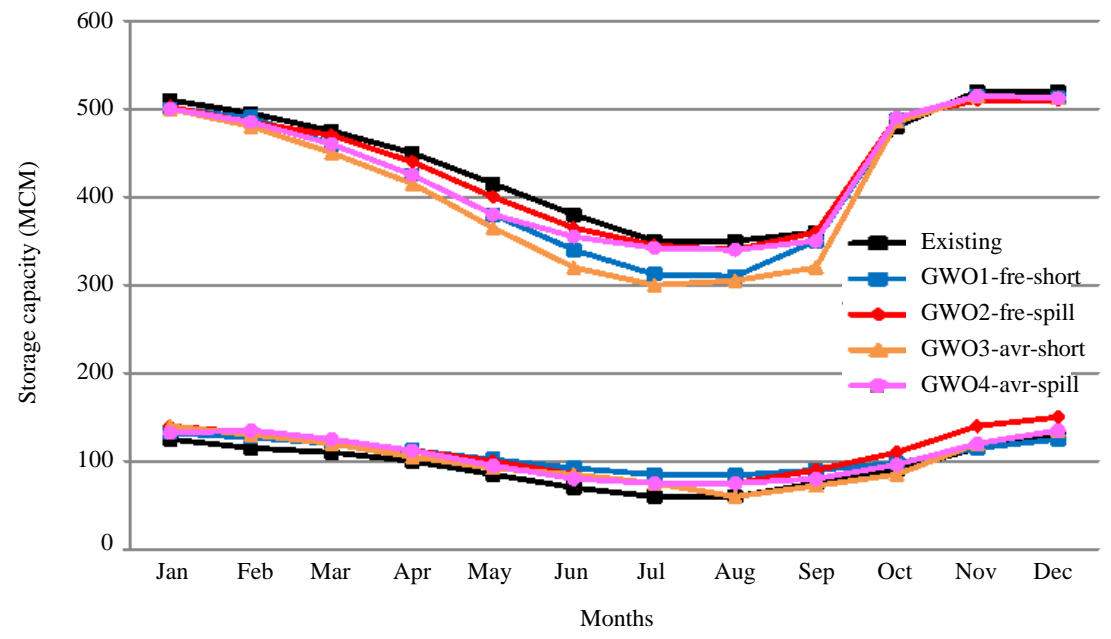

Fig. 8: Optimal rule curves of Nam Oon reservoir

Figure 8 shows the optimal rule curves of Nam Oon reservoir for all objective functions as well as the existing rule curves. It indicates that GWO1-fre-short, GWO2-fre-spill, GWO3-avr-short and GWO4-avr-spill represent the obtained rule curves from the proposed model considering the minimal frequency of water shortage, the minimal frequency of excess water, the minimal average water shortage and the minimal average excess water as the objective function in searching procedure, respectively. They present that the new upper rule curves are lower than the existing rule curves during January to September for all objective function. Whereas the new lower rule curves during January to July are higher than the existing lower rule curves for all objective function. In conclude their patterns are similar like the previous study (Kangrang et al., 2018).
Evaluation of the model's effectiveness: Table 1 shows the evaluation of the obtained rule curves and the existing rule curves considering the historic inflow during 1970-2017 for the Ubolratana reservoir. It indicates that the situations of water shortage of using GWO3-avr-short rule curves are the least as compared with the other rule curves for frequency, magnitude and duration of 0.195 times/year, $50.887 \mathrm{MCM}$ and 1.473 years, respectively. Whereas the situations of excess water of using GWO4-avr-spill rule curves are the least as compared with the others rule curves for frequency, magnitude and duration of 0.383 times/year, $544.914 \mathrm{MCM}$ and 3.710 years.

Table 2 shows the evaluation of the obtained rule curves and the existing rule curves considering the 1,000 samples of synthetic inflow for the Ubolratana reservoir. 
Table 1: Situation of water shortage and excess water of Ubolratana reservoir considering historic inflow data

\begin{tabular}{|c|c|c|c|c|c|}
\hline \multirow[b]{2}{*}{ Situation/Rule curves } & \multirow{2}{*}{$\begin{array}{l}\text { Frequencies } \\
\text { (times/year) }\end{array}$} & \multicolumn{2}{|c|}{ Volume (MCM) } & \multicolumn{2}{|c|}{ Time period (year) } \\
\hline & & Average & Maximum & Average & Maximum \\
\hline \multicolumn{6}{|l|}{ Shortage } \\
\hline Existing & 0.262 & 66.502 & 345.774 & 1.592 & 2.471 \\
\hline GWO1-fre-short & 0.202 & 51.895 & 333.768 & 1.531 & 2.227 \\
\hline GWO2-fre-spill & 0.207 & 64.904 & 340.126 & 1.564 & 2.275 \\
\hline GWO3-avr-short & 0.195 & 50.887 & 304.791 & 1.473 & 1.774 \\
\hline GWO4-avr-spill & 0.224 & 61.973 & 342.046 & 1.610 & 2.253 \\
\hline \multicolumn{6}{|l|}{ Excess water } \\
\hline Existing & 0.416 & 553.642 & 1895.761 & 4.087 & 8.764 \\
\hline GWO1-fre-short & 0.410 & 547.846 & 1886.745 & 3.842 & 8.167 \\
\hline GWO2-fre-spill & 0.425 & 550.432 & 1874.397 & 4.084 & 8.604 \\
\hline GWO3-avr-short & 0.412 & 551.784 & 1901.118 & 4.007 & 8.769 \\
\hline GWO4-avr-spill & 0.383 & 544.914 & 1880.728 & 3.710 & 8.341 \\
\hline
\end{tabular}

Table 2 Situation of water shortage and excess water of Ubolratana reservoir considering synthetic inflow data for 1,000 samples

\begin{tabular}{|c|c|c|c|c|c|}
\hline \multirow[b]{2}{*}{ Situation/Rule curves } & \multirow{2}{*}{\begin{tabular}{l} 
Frequencies \\
\hdashline (times/year) \\
\end{tabular}} & \multicolumn{2}{|c|}{ Volume (MCM) } & \multicolumn{2}{|c|}{ Time period (year) } \\
\hline & & Average & Maximum & Average & Maximum \\
\hline \multicolumn{6}{|l|}{ Shortage: } \\
\hline \multicolumn{6}{|l|}{ Existing } \\
\hline$\mu$ & 0.121 & 31.343 & 293.157 & 1.097 & 1.487 \\
\hline$\sigma$ & 0.011 & 0.009 & 0.010 & 0.002 & 0.003 \\
\hline \multicolumn{6}{|l|}{ GWO1-fre-short } \\
\hline$\mu$ & 0.156 & 30.271 & 292.066 & 1.102 & 1.424 \\
\hline$\sigma$ & 0.011 & 0.007 & 0.008 & 0.002 & 0.004 \\
\hline \multicolumn{6}{|l|}{ GWO2-fre-spill } \\
\hline$\mu$ & 0.149 & 30.446 & 293.148 & 1.121 & 1.425 \\
\hline$\sigma$ & 0.010 & 0.009 & 0.010 & 0.007 & 0.009 \\
\hline \multicolumn{6}{|l|}{ GWO3-avr-short } \\
\hline$\mu$ & 0.145 & 30.315 & 292.884 & 1.118 & 1.437 \\
\hline$\sigma$ & 0.012 & 0.009 & 0.010 & 0.003 & 0.005 \\
\hline \multicolumn{6}{|l|}{ GWO4-avr-spill } \\
\hline$\mu$ & 0.153 & 29.945 & 293.042 & 1.100 & 1.444 \\
\hline$\sigma$ & 0.013 & 0.010 & 0.011 & 0.003 & 0.005 \\
\hline \multicolumn{6}{|l|}{ Excess water: } \\
\hline \multicolumn{6}{|l|}{ Existing } \\
\hline$\mu$ & 0.382 & 514.276 & 294.002 & 2.103 & 3.473 \\
\hline$\sigma$ & 0.002 & 0.003 & 0.005 & 0.004 & 0.005 \\
\hline \multicolumn{6}{|l|}{ GWO1-fre-short } \\
\hline$\mu$ & 0.347 & 514.197 & 1907.328 & 1.976 & 3.292 \\
\hline$\sigma$ & 0.011 & 0.008 & 0.009 & 0.003 & 0.004 \\
\hline \multicolumn{6}{|l|}{ GWO2-fre-spill } \\
\hline$\mu$ & 0.287 & 513.864 & 1906.876 & 2.003 & 3.246 \\
\hline$\sigma$ & 0.001 & 0.003 & 0.005 & 0.002 & 0.003 \\
\hline \multicolumn{6}{|l|}{ GWO3-avr-short } \\
\hline$\mu$ & 0.329 & 514.078 & 1906.458 & 2.010 & 3.274 \\
\hline$\sigma$ & 0.001 & 0.000 & 0.001 & 0.001 & 0.002 \\
\hline \multicolumn{6}{|l|}{ GWO4-avr-spill } \\
\hline$\mu$ & 0.340 & 513.461 & 1907.007 & 2.002 & 3.198 \\
\hline$\underline{\sigma}$ & 0.001 & 0.001 & 0.002 & 0.001 & 0.002 \\
\hline
\end{tabular}

$\mu=$ Average, $\sigma=$ Standard deviation

It indicates that the situations of water shortage of using GWO3-avr-short rule curves are the least as compared with the other rule curves for frequency, magnitude and duration of $0.145 \pm 0.012$ times/year, $30.315 \pm 0.009 \mathrm{MCM}$ and $1.118 \pm 0.003$ years, respectively. Whereas the situations of excess water of using GWO4-avr-spill rule curves are the least as compared with the others rule curves for frequency, magnitude and duration of $0.340 \pm 0.001$ times/year, $513.461 \pm 0.001 \mathrm{MCM}$ and $2.002 \pm 0.001$ years, respectively. The trends of these results are similar to the previous studies (Hormwichian et al., 2009; Kangrang et al., 2016, 2018).

Table 3 shows the evaluation of the obtained rule curves and the existing rule curves considering the historic inflow during 1971-2017 for the Lampao reservoir. It indicates that the situations of water shortage of using GWO3-avr-short rule curves are the least as compared with the other rule curves for frequency, magnitude and duration of 0.397 times/year, 518.072 MCM and 21.012 
Table 3: Situation of water shortage and excess water of Lampao reservoir considering historic inflow data

\begin{tabular}{|c|c|c|c|c|c|}
\hline \multirow[b]{2}{*}{ Situation/Rule curves } & \multirow{2}{*}{$\begin{array}{l}\text { Frequencies } \\
\text { (times/year) }\end{array}$} & \multicolumn{2}{|c|}{ Volume (MCM) } & \multicolumn{2}{|c|}{ Time period (year) } \\
\hline & & Average & Maximum & Average & Maximum \\
\hline \multicolumn{6}{|l|}{ Shortage } \\
\hline Existing & 0.484 & 678.742 & 803.719 & 21.149 & 21.744 \\
\hline GWO1-fre-short & 0.433 & 594.763 & 764.085 & 20.974 & 21.985 \\
\hline GWO2-fre-spill & 0.445 & 588.761 & 753.418 & 20.861 & 21.986 \\
\hline GWO3-avr-short & 0.397 & 581.072 & 744.264 & 21.012 & 21.074 \\
\hline GWO4-avr-spill & 0.461 & 591.554 & 756.748 & 20.876 & 21.871 \\
\hline \multicolumn{6}{|l|}{ Excess water } \\
\hline Existing & 0.376 & 210.711 & 293.716 & 2.111 & 7.804 \\
\hline GWO1-fre-short & 0.301 & 198.972 & 281.651 & 1.985 & 7.422 \\
\hline GWO2-fre-spill & 0.318 & 210.531 & 282.439 & 2.014 & 7.431 \\
\hline GWO3-avr-short & 0.297 & 208.679 & 285.106 & 1.984 & 7.397 \\
\hline GWO4-avr-spill & 0.202 & 197.222 & 272.778 & 1.971 & 6.985 \\
\hline
\end{tabular}

Table 4: Situation of water shortage and excess water of Lampao reservoir considering synthetic inflow data for 1,000 samples

\begin{tabular}{|c|c|c|c|c|c|}
\hline \multirow[b]{2}{*}{ Situation/Rule curves } & \multirow{2}{*}{$\begin{array}{l}\text { Frequencies } \\
\text { (times/year) }\end{array}$} & \multicolumn{2}{|c|}{ Volume (MCM) } & \multicolumn{2}{|c|}{ Time period (year) } \\
\hline & & Average & Maximum & Average & Maximum \\
\hline \multicolumn{6}{|l|}{$\begin{array}{l}\text { Shortage: } \\
\text { Existing }\end{array}$} \\
\hline$\mu$ & 0.427 & 678.329 & 802.441 & 22.769 & 22.773 \\
\hline$\sigma$ & 0.052 & 6.707 & 6.974 & 2.643 & 2.874 \\
\hline \multicolumn{6}{|l|}{ GWO1-fre-short } \\
\hline$\mu$ & 0.418 & 7.008 & 802.176 & 22.754 & 22.862 \\
\hline$\sigma$ & 0.074 & 6.879 & 6.832 & 2.414 & 2.561 \\
\hline \multicolumn{6}{|l|}{ GWO2-fre-spill } \\
\hline$\mu$ & 0.422 & 7.210 & 801.754 & 22.745 & 22.807 \\
\hline$\sigma$ & 0.044 & 6.448 & 6.340 & 2.228 & 2.741 \\
\hline \multicolumn{6}{|l|}{ GWO3-avr-short } \\
\hline$\mu$ & 0.416 & 676.212 & 801.642 & 22.598 & 22.712 \\
\hline$\sigma$ & 0.046 & 6.178 & 6.227 & 2.192 & 2.461 \\
\hline \multicolumn{6}{|l|}{ GWO4-avr-spill } \\
\hline$\mu$ & 0.421 & 676.841 & 802.005 & 22.727 & 22.813 \\
\hline$\sigma$ & 0.075 & 6.607 & 6.846 & 2.348 & 2.485 \\
\hline \multicolumn{6}{|l|}{ Excess water: } \\
\hline \multicolumn{6}{|l|}{ Existing } \\
\hline$\mu$ & 0.245 & 153.297 & 294.103 & 1.022 & 2.877 \\
\hline$\sigma$ & 0.034 & 2.074 & 3.872 & 0.020 & 0.754 \\
\hline \multicolumn{6}{|l|}{ GWO1-fre-short } \\
\hline$\mu$ & 0.227 & 152.671 & 292.139 & 1.018 & 2.805 \\
\hline$\sigma$ & 0.082 & 2.302 & 2.074 & 0.042 & 0.786 \\
\hline \multicolumn{6}{|l|}{ GWO2-fre-spill } \\
\hline$\mu$ & 0.159 & 152.643 & 292.457 & 1.406 & 2.846 \\
\hline$\sigma$ & 0.048 & 2.047 & 2.395 & 0.003 & 0.821 \\
\hline \multicolumn{6}{|l|}{ GWO3-avr-short } \\
\hline$\mu$ & 0.176 & 152.589 & 292.642 & 1.208 & 2.852 \\
\hline$\sigma$ & 0.047 & 2.224 & 2.271 & 0.001 & 0.822 \\
\hline \multicolumn{6}{|l|}{ GWO4-avr-spill } \\
\hline$\mu$ & 0.176 & 152.505 & 292.098 & 1.006 & 2.827 \\
\hline$\sigma$ & 0.004 & 2.238 & 2.210 & 0.001 & 0.834 \\
\hline
\end{tabular}

$\mu=$ Average, $\sigma=$ Standard deviation

years, respectively. Whereas the situations of excess water of using GWO4-avr-spill rule curves are the least as compared with the others rule curves for frequency, magnitude and duration of 0.202 times/year, $197.222 \mathrm{MCM}$ and 1.971 years.

Table 4 shows the evaluation of the obtained rule curves and the existing rule curves considering the 1,000 samples of synthetic inflow for the Lampao reservoir. It indicates that the situations of water shortage of using GWO3-avr-short rule curves are the least as compared with the other rule curves for frequency, magnitude and duration of $0.416 \pm 0.046$ times/year, $676 \pm 0.212 \mathrm{MCM}$ and $22.598 \pm 2.192$ years, respectively. Whereas the situations of excess water of using GWO4-avr-spill rule curves are the least as compared with the others rule curves for frequency, magnitude and duration of $0.176 \pm 0.001$ times/year, $292.098 \pm 2.210 \mathrm{MCM}$ and $1.006 \pm 0.001$ years, respectively. The trends of these results are similar to the previous studies (Hormwichian et al., 2009; Kangrang et al., 2016). 
Table 5: Situation of water shortage and excess water of Nam Oon reservoir considering historic inflow data

\begin{tabular}{|c|c|c|c|c|c|}
\hline \multirow[b]{2}{*}{ Situation/Rule curves } & \multirow{2}{*}{$\begin{array}{l}\text { Frequencies } \\
\text { (times/year) }\end{array}$} & \multicolumn{2}{|c|}{ Volume (MCM.) } & \multicolumn{2}{|c|}{ Time period (year) } \\
\hline & & Average & Maximum & Average & Maximum \\
\hline \multicolumn{6}{|l|}{ Shortage } \\
\hline Existing & 0.000 & 0.000 & 0.000 & 0.000 & 0.000 \\
\hline GWO1-fre-short & 0.000 & 0.000 & 0.000 & 0.000 & 0.000 \\
\hline GWO2-fre-spill & 0.000 & 0.000 & 0.000 & 0.000 & 0.000 \\
\hline GWO3-avr-short & 0.000 & 0.000 & 0.000 & 0.000 & 0.000 \\
\hline GWO4-avr-spill & 0.000 & 0.000 & 0.000 & 0.000 & 0.000 \\
\hline \multicolumn{6}{|l|}{ Excess water } \\
\hline Existing & 0.398 & 105.812 & 217.715 & 4. 721 & 8.942 \\
\hline GWO1-fre-short & 0.377 & 104.874 & 217.643 & 4.885 & 8.741 \\
\hline GWO2-fre-spill & 0.347 & 105.631 & 216.439 & 4.608 & 8.738 \\
\hline GWO3-avr-short & 0.364 & 104.638 & 217.306 & 4.594 & 8.739 \\
\hline GWO4-avr-spill & 0.355 & 104.452 & 216.378 & 4.592 & 8.734 \\
\hline
\end{tabular}

Table 6: Situation of water shortage and excess water of Nam Oon reservoir considering synthetic inflow data for 1,000 samples

\begin{tabular}{|c|c|c|c|c|c|}
\hline \multirow[b]{2}{*}{ Situation/Rule curves } & \multirow{2}{*}{$\begin{array}{l}\text { Frequencies } \\
\text {-(times/year) } \\
\end{array}$} & \multicolumn{2}{|c|}{ Volume (MCM.) } & \multicolumn{2}{|c|}{ Time period (year) } \\
\hline & & Average & Maximum & Average & Maximum \\
\hline \multicolumn{6}{|l|}{ Shortage: } \\
\hline \multicolumn{6}{|l|}{ Existing } \\
\hline$\mu$ & 0.000 & 0.000 & 0.000 & 0.000 & 0.000 \\
\hline$\sigma$ & 0.000 & 0.000 & 0.000 & 0.000 & 0.000 \\
\hline \multicolumn{6}{|l|}{ GWO1-fre-short } \\
\hline$\mu$ & 0.000 & 0.000 & 0.000 & 0.000 & 0.000 \\
\hline$\sigma$ & 0.000 & 0.000 & 0.000 & 0.000 & 0.000 \\
\hline \multicolumn{6}{|l|}{ GWO2-fre-spill } \\
\hline$\mu$ & 0.000 & 0.000 & 0.000 & 0.000 & 0.000 \\
\hline$\sigma$ & 0.000 & 0.000 & 0.000 & 0.000 & 0.000 \\
\hline \multicolumn{6}{|l|}{ GWO3-avr-short } \\
\hline$\mu$ & 0.000 & 0.000 & 0.000 & 0.000 & 0.000 \\
\hline$\sigma$ & 0.000 & 0.000 & 0.000 & 0.000 & 0.000 \\
\hline \multicolumn{6}{|l|}{ GWO4-avr-spill } \\
\hline$\mu$ & 0.000 & 0.000 & 0.000 & 0.000 & 0.000 \\
\hline$\sigma$ & 0.000 & 0.000 & 0.000 & 0.000 & 0.000 \\
\hline \multicolumn{6}{|l|}{ Excess water: } \\
\hline \multicolumn{6}{|l|}{ Existing } \\
\hline$\mu$ & 0.451 & 108.497 & 220.715 & 3.642 & 8.738 \\
\hline$\sigma$ & 0.004 & 0.009 & 0.045 & 0.002 & 0.002 \\
\hline \multicolumn{6}{|l|}{ GWO1-fre-short } \\
\hline$\mu$ & 0.449 & 108.245 & 219.075 & 2.527 & 7.536 \\
\hline$\sigma$ & 0.002 & 0.005 & 0.006 & 0.001 & 0.001 \\
\hline \multicolumn{6}{|l|}{ GWO2-fre-spill } \\
\hline$\mu$ & 0.427 & 108.241 & 211.108 & 2.615 & 7.740 \\
\hline$\sigma$ & 0.007 & 0.004 & 0.006 & 0.001 & 0.002 \\
\hline \multicolumn{6}{|l|}{ GWO3-avr-short } \\
\hline$\mu$ & 0.429 & 108.239 & 212.396 & 2.784 & 8.207 \\
\hline$\sigma$ & 0.004 & 0.008 & 0.009 & 0.005 & 0.007 \\
\hline \multicolumn{6}{|l|}{ GWO4-avr-spill } \\
\hline$\mu$ & 0.435 & 107.397 & 210.159 & 2.514 & 7.344 \\
\hline$\sigma$ & 0.007 & 0.005 & 0.004 & 0.003 & 0.002 \\
\hline
\end{tabular}

$\mu=$ Average, $\sigma=$ Standard deviation

Table 5 shows the evaluation of the obtained rule curves and the existing rule curves considering the historic inflow during 1993-2017 for the Nam Oon reservoir. It indicates that the situations of water shortage of using all new obtained rule curves are zero because of total inflow quite greater than total demand. Therefore, the situations of excess water of using GWO4-avr-spill rule curves are the least as compared with the others rule curves for frequency, magnitude and duration of 0.355 times/year, 104.452 MCM and 4.592 years.
Table 6 shows the evaluation of the obtained rule curves and the existing rule curves considering the 1,000 samples of synthetic inflow for the Nam Oon reservoir. It indicates that the situations of water shortage of using all new obtained rule curves are zero because of total inflow quite greater than total demand. Whereas the situations of excess water of using GWO4-avr-spill rule curves are the least as compared with the others rule curves for frequency, magnitude and duration of $0.435 \pm 0.007$ times/year, 107.397 $\pm 0.005 \mathrm{MCM}$ 
and $2.514 \pm 0.003$ years, respectively. The trends of these results are similar to the previous study (Kangrang et al., 2019).

\section{CONCLUSION}

This study applied the Gray Wolf Optimizer technique (GWO) connecting with reservoir simulation model in order to search optimal rule curves. There were 4 objective functions including; the minimal frequency of water shortage, the minimal frequency of excess release water, the minimal average water shortage and the minimal average excess release water that used to search optimal rule curves for all reservoirs. The considered reservoirs for this study were the Ubolratana reservoir, the Lampao reservoir and the Nam Oon reservoir these were located in the Northeast Region of Thailand. The results found that the obtained rule curves from the proposed model using all objective functions having the shape similar to the shape of existing rule curves for all reservoirs. Because the searching conditions were fixed as the same, so, the obtained shapes were similar. However, some important months were quite different. All obtained rule curves were used to assess the situation of water shortage and excess water using the reservoir simulation model considering the synthetic inflow for all reservoirs. The results shown that the water shortage of the new rule curves were less than the water shortage of the existing rule curves. Moreover, the excess water of the new obtained rule curves were less than the excess water of the existing rule curves too. Furthermore, the objective function of minimal average water shortage can mitigate excess water and water shortage situations better than other objective functions. In conclude the GWO connecting with reservoir simulation model with the objective function of minimal average water shortage can apply to find the optimal rule curves effectively.

\section{ACKNOWLEDGEMENT}

This research was financially supported by Mahasarakham University and National Research Council of Thailand Grant Year 2019; the researchers would like to acknowledge Mahasarakham University and National Research Council of Thailand.

\section{REFERENCES}

Afshar, A., F. Massoumi, A. Afshar and M.A. Marino, 2015. State of the art review of ant colony optimization applications in water resource management. Water Resour. Manage., 29: 3891-3904.
Afshar, M.H., 2013. Extension of the constrained particle swarm optimization algorithm to optimal operation of multi-reservoirs system. Int. J. Electr. Power Energy Syst., 51: 71-81.

Akinro, A.O., M.O. Alatise and O.O. Olanrewaju, 2007. Combining rippls mass curve and loucks sequent peak procedureto determine reservoir capacity: The case study of owena river in Ondo State, Nigeria. J. Eng. Applied Sciences, 2: 1470-1475.

Chaleeraktrakoon, C. and A. Kangrang, 2007. Dynamic programming with the principle of progressive optimality for searching rule curves. Can. J. Civil Eng., 34: 170-176.

Chang, J.F., L. Chen and C.L. Chang, 2005. Optimizing the reservoir operating rule curves by genetic algorithms. Hydrol. Process., 19: 2277-2289.

El-Fergany, A.A. and H.M. Hasanien, 2015. Single and multi-objective optimal power flow using grey wolf optimizer and differential evolution algorithms. Electr. Power Compon. Syst., 43: 1548-1559.

Hematpour, H., S.M. Mahmood, S. Akbari and N.H. Nasr, 2017. Comparison study on sag foam model parameters in different reservoir simulators. J. Eng. Appl. Sci., 12: 5373-5378.

Hormwichian, R., A. Kangrang and A. Lamom, 2009. A conditional genetic algorithm model for searching optimal reservoir rule curves. J. Applied Sci., 9: 3575-3580.

Hormwichian, R., J. Tongsiri and A. Kangrang, 2018. Multipurpose rule curves for multipurpose reservoir by conditional genetic algorithm. Intl. Rev. Civil Eng., 9: 114-121.

Hossain, S., 2016. A reservoir release optimizationsimulation model using Particle Swarm Optimization (PSO) algorithm. J. Eng. Appl. Sci., 11: 2186-2192.

Jain, K.S., K.M. Goel and K.P. Agarwal, 1998. Reservoir operation study of sabamati system, India. J. Water Res. Plan. Manage., 124: 31-38.

Janoski, G., S. Mukkamala and A.H. Sung, 2006. A comparison of soft computing methods for reservoir simulation. Intl. J. Soft Comput., 1: 207-214.

Jebaraj, N.R.S. and H.R. Keshavan, 2017. Optimizing the ZigBee networks lifetime with a grey wolf algorithm. Asian J. Inf. Technol., 16: $472-478$.

Ji, C., Z. Jiang, P. Sun, Y. Zhang and L. Wang, 2014. Research and application of multidimensional dynamic programming in cascade reservoirs based on multilayer nested structure. J. Water Resour. Plann. Manage., Vol. 141, No. 7. 10.1061/(ASCE)WR.1943-5452.0000489 
Kangrang, A., H. Prasanchum and R. Hormwichian, 2018. Development of future rule curves for multipurpose reservoir operation using conditional genetic and Tabu search algorithms. Adv. Civil Eng., 2018: $1-10$.

Kangrang, A., R. Techarungruengsakul, R. Hormwichian and O. Sriwanpheng, 2019. Alternative approach of wind driven optimization for flood control rule curves. J. Eng. Appl. Sci., 14: 8026-8033.

Kangrang, A., W. Pakoktom, W. Nuannukul and C. Chaleeraktrakoon, 2016. Adaptive reservoir rule curves by optimisation and simulation. Proc. Inst. Civil Eng.-Water Manage., 170: 219-230.

Kumar, D.N., F. Baliarsingh and K.S. Raju, 2010. Optimal reservoir operation for flood control using folded dynamic programming. Water Resour. Manage., 24: 1045-1064.

M-Dawam, S.R. and K.R. Ku-Mahamud, 2016. Predictive modelling for reservoir water level. Res. J. Appl. Sci., 11: 851-857.

Ming, B., J.X. Chang, Q. Huang, Y.M. Wang and S.Z. Huang, 2015. Optimal operation of multireservoir system based-on cuckoo search algorithm. Water Resour. Manage., 29: 5671-5687.
Mirjalili, S., S.M. Mirjalili and A. Lewis, 2014. Grey wolf optimizer. Adv. Eng. Software, 69: 46-61.

Prasanchum, H. and A. Kangrang, 2018. Optimal reservoir rule curves under climatic and land use changes for Lampao Dam using genetic algorithm. KSCE. J. Civil Eng., 22: 351-364.

Saremi, S., S.Z. Mirjalili and S.M. Mirjalili, 2015. Evolutionary population dynamics and grey wolf optimizer. Neural Comput. Appl., 26: 1257-1263.

Sivanpheng, O. and A. Kangrang, 2015. Water resource management of a pilot irrigation scheme in Lao PDR. Philippine Agric. Sci., 98: 209-223.

Sulaiman, M.H., Z. Mustaffa, M.R. Mohamed and O. Aliman, 2015. Using the gray wolf optimizer for solving optimal reactive power dispatch problem. Appl. Soft Comput., 32: 286-292.

US Army Corps of Engineers, 1974. Reservoir System Analysis for Conservation, User's Manual. Hydrologie Engineering Center, Davis, California, USA.

Zhou, Y. and S. Guo, 2013. Incorporating ecological requirement into multipurpose reservoir operating rule curves for adaptation to climate change. J. Hydrol., 498: 153-164. 